\title{
Art, Law and Unstable Corporate Identities
}

\author{
Jeremy Pilcher \\ Birkbeck School of Law \\ University of London, UK \\ j.pilcher@bbk.ac.uk
}

\begin{abstract}
Art has used the tactic of parasitism, which has included the appropriation of intellectual property such as brand images, to challenge the accumulation and exploitation of consumer data in the socalled co-creation of corporate identity. This is greatly facilitated by online real-time technologies. Corporations understand brands to capture the identity of an organisation. Intellectual property laws are used to protect brands in the crucial commercial process of the formation, stabilisation and manipulation of corporate identity. In TM Clubcard (1997) Rachel Baker employed direct lifts of supermarket logos to parasite Tesco's 'Clubcard,' which was the UK's first supermarket loyalty card scheme. The work associated the supermarket brand with what Baker called a "dysfunctional" database of members. Tesco threatened legal action, which led to Baker re-directing TM Clubcard towards another supermarket: Sainsbury's. TM Clubcard collected personal details, and together with a claim that the work was deceptive, one of the supermarkets also asserted that it was entitled to this data. The work was brought to an end after a warning from law firms that legal proceedings would be issued. Baker explicitly situated the appropriation of the supermarkets' brands by TM Clubcard in the context of Duchamp's ready-mades. The implications of such art for identity construction may be engaged with through the performative after Derrida. A stark opposition between the law and art is too simplistic. The intersection between the two opens the possibility of engaging with the violence of the law as exemplified in the ways it structures and forecloses the ways that identities may be created and perpetuated. This violence is intertwined with the law's claims to being ahistorical and acontextual. Art invites inventive encounters with the contingencies and constraints of the legal system(s) by which it is simultaneously both threatened and enabled.
\end{abstract}

Art. Law. Branding. Corporation. Company. Intellectual property. Trademark.

\section{INTRODUCTION}

Art has a history of appropriating objects and imagery found in the visual environment, often contrary to a variety of laws creating intellectual property rights. The array of such works includes art as diverse as Marcel Duchamp's L.H.O.O.Q and Hans Haacke's Metromobilitan, which led to Haacke being threatened with trade mark infringement by Mobil (McClean \& Schubert 2002) through to more recent projects such as Amazon Noir by Ubermorgen.com, Paolo Cirio, and Alessandro Ludovico.

The susceptibility of material online to be copied and re-contextualised has meant the Internet has proved to be an effective site for the creation of politically charged work that critiques capitalism and the ownership of intellectual property. The wide-ranging nature of such work is discussed elsewhere and there is not the scope here to do more than acknowledge its depth and variety (see for example: Paul 2003; Harold 2004; Gibbons 2005; Raley 2009). The law has been used by companies to prevent such art with the result it has been accused of restraining the 'ability to cite freely, to purloin images that are salient within the general culture, to pursue a conversation without vetting by lawyers' (Stallabrass 2003, p.104). It has been suggested that intellectual property rights should not apply on the Internet (Paul 2003, pp.210-11). Clearly such art may infringe existing intellectual property rights, such as copyright and trademarks.

My argument is that the way in which art may appropriate the intellectual property of others should not obscure the way that such work, whether on the Internet or elsewhere, may amount to a more sophisticated engagement than a simple infringement of the law. This is illustrated by the work of art entitled TM Clubcard. Art that appropriates is able to open the need for a decision as to whether it belongs to the world of art or the 'everyday'. In the process it may be understood as a provocation because it directs attention to the violence of the law and the way that may be used in an attempt to foreclose the change that may be 
brought about and understood through iterability. I have discussed this elsewhere in relation to installation art (Pilcher 2016). Very briefly, iterability conveys the inevitable and unavoidable possibility of rupture in the process of identity perpetuation given that the on-going presence of something may only be understood by "reference to something else, thus rending the full presence that it nevertheless announces" (Derrida 1988, p.129).

I will further argue that art that appropriates may also have the effect of opening awareness that the law is not a neutral means to achieve social order. A work such as TM Clubcard is able to provoke the realisation that, in disavowing iterability, the law privileges programmatic decision-making by favouring the pursuit of profit over critical and inventive thinking. It is by means of allowing the risk of such thinking that leaves open the promise that society can be better in the future.

\section{TM CLUBCARD}

TM Clubcard was a website set up by Rachel Baker in 1997. The work mimicked the Tesco supermarket loyalty card scheme using appropriated supermarket branding. Tesco took the work seriously. In a letter dated 21 April 1997 from the firm of solicitors Willoughby \& Partners, legal action was threatened in order to protect Tesco's intellectual property rights if TM Clubcard was not brought to an end (Baker 2019). Baker describes how in response she employed a strategy that involved the work changing its target from Tesco to the supermarket Sainsbury. A letter dated 2 July 1997 duly arrived from Sainsbury's solicitors, Denton Hall. This letter similarly alleged that TM Clubcard was infringing intellectual property rights and included the assertion that anyone viewing TM Clubcard was "likely to be misled into thinking that your site is in some way associated with or sanctioned by Sainsburys [sic], when this is not the case" (Baker 2019).

The work now only exists online in an archive form. Although TM Clubcard may have infringed the supermarkets' intellectual property rights, the work's provocative effect is inextricably linked to the threat it posed to corporate identity. As Baker observed, in appropriating the supermarkets' brands by using their trademarks, the work took advantage of the way in which on the web "all identities, including those cultivated by big companies, are unstable, insecure, providing the opportunity, for those with the desire, to change/intercept the relationship with a brand name or distort its meaning" (Baker 1997).

Although it may be particularly easy to decontextualise images online, any appropriation that opens a critical awareness of the contingent meaning of a corporate brand is problematic for companies. In order for a brand to be a success in the formation of corporate identity, which is ultimately measured in terms of a company's profitability, ideally the meaning that is associated with its trademark needs to be constructed within a context that has been framed by that company. As argued by Martin Kornberger, "brands are identities-in-action that allow stability to be maintained while simultaneously enabling change" (2010, p.87).

To ensure that a brand message is associated with any given trademark a company will seek to control the context in which it is viewed and understood. The respective threats of legal proceedings by the supermarkets may be considered to have been attempts to use intellectual property rights to achieve such fixity. The point is encapsulated by Celia Lury, "trade mark law does more than protect the mark owner from unfair forms of competition. It makes it possible for trade mark owners to establish and lay claim to property rights in new forms of object-ivity while only minimally acknowledging the implicatedness of the activities of consumers in this objectivity" (Lury 2004, p.14). The importance of brands to corporate identity needs to be understood in terms of the nature of corporations.

In very brief terms, a company may be incorporated as a separate legal personality with its shareholders enjoying limited liability. This means that that the company's liabilities are the legal responsibility of the company and the shareholders will not be responsible for the company's debts (Talbot 2008). This often means that creditors or employees who are unable to recover what they are owed from an insolvent company that does not have sufficient assets to pay off its debts, will be unable to do so from the shareholders or the directors. The company structure may be understood to have the effect of protecting the distributed networks of people that lie behind the company (shareholders) and/or through whom the company acts (directors).

A company, as a separate legal personality, uses various and co-implicated methods to build, out of the distributed groups of people from which it is formed, the perception of a discrete entity distinguishable from its competitors. The many elements that contribute to such an identity include a company's mission statement; the behaviour of the company as expressed through the way customers are treated; the way in which its products are priced; the spectrum of products offered by the company; the geographical 'roots' of the company (e.g. whether it is a local business); its longevity; any slogans used; and also any 
benefits which accrue to its customers. The brand of a company provides a gathering point for each of the elements involved in the construction of its identity.

TM Clubcard appropriated the branding of supermarkets and in doing so had the effect of uncovering the asymmetric process of construction (legally weighted in favour corporations) underlying the supermarkets' identities. This process may be identified in a wide range of other art/activism projects that, in broad terms, create politically charged work that critiques capitalism and the ownership of intellectual property (Paul 2003; Harold 2004; Gibbons 2005; Raley 2009).

It is particularly interesting how TM Clubcard created a 'living' contrast between itself and the authentic Tesco loyalty card scheme. The work did so by acquiring and distributing loyalty cards via a site that employed direct lifts of the supermarkets' logos. At the same time the appropriated supermarket branding was associated with a "dysfunctional" TM Clubcard database (Baker 1997). Visitors to the work could become aware that TM Clubcard was a parody due to a number of the work's features, including the requirement for those who wished to apply for a mock loyalty card to answer questions rewritten from those on the supermarket's application forms. For example, on the questionnaire under the heading "Personal Pleasure" was the question "What do you prefer?" and response options included "shopping", "driving", and "sex" (Baker 2019). Willoughby \& Partners and Denton Hall characterised this conduct as a "deception" and on behalf of the supermarkets' sought an undertaking that required the site be brought to an end (Baker 2019).

The alleged deception directed attention to the way in which corporate identity, despite anyone's best efforts, cannot entirely be controlled. The assertion of intellectual property rights online by the supermarkets was an attempt to prevent the risk to corporate identity that results from a brand being contextualised in a way not desired by a company. Threats of legal action may be understood as illustrating how the law can be employed in ways that close off the possibility for an awareness of how individual identities and society could be differently constructed.

My discussion of the way in which TM Clubcard engaged in this process starts with Rachel Baker expressly situated the appropriation of the supermarkets' intellectual property by TM Clubcard in the context of Duchamp's readymades (Baker 1997). One of the most famous readymades is Fountain, which was a rotated men's urinal placed on a plinth. Since Duchamp art has, by means of appropriation, detached the 'everyday' from its ordinary use. In the process it may give rise to an undecidable oscillation between how it is understood and so require the need for a decision between the possibilities that are opened.

My argument turns on an understanding of art that appropriates corporate branding protected by intellectual property laws in terms of the work of Jacques Derrida. In particular, Duchamp's readymades and appropriative art more generally may be understood through Derrida's writing on performatives (1988). On the one hand he has shown the context of a performative can never be saturated. An author's intentions when employing a performative are relevant but are not finally determinative of meaning $(1988, p .18)$. It was, for example, not clear that Duchamp actually had any intention in 1917 that the work should come to be art. Louise Norton, writing contemporaneously, remarked in response to those who asked if Duchamp was serious or joking: 'Perhaps he is both!' (Ades, Cox \& Hopkins, p.1999). On the other hand, even if a work complies with established cultural criteria (e.g. signature; plinth), it may still not (come to) be regarded as art. By detaching brand images from the context framed by the supermarkets, TM Clubcard directed attention to the way iterability has the same implications for branding.

\section{BRANDING AND THE LAW}

In order for a brand to convey an intended meaning it must be repeatable. Yet, with that repetition comes a change in context and the brand is opened to a decision about the meaning signified by it, which may be different from that intended (by, for example, a supermarket). By asserting copyright and other legal rights, the supermarkets sought to foreclose an engagement with the iterability of their brands, so preventing their use in the artwork. In the process the companies effectively disavowed the very possibility that allows any meaning at all to be constructed. The provocation of TM Clubcard may be understood in wider terms than the threat it posed to corporate identity; it also drew attention to the iterability of the law.

As Derrida argues in 'Force of Law', the violence of the foundation of the law must be iterable in order for it to have an on-going legitimacy (1990). Every time a law is applied in different contexts, such as when a company is formed or asserts its rights, the authority of the law's institutive founding violence is re-iterated. This means that violence both founds and conserves a legal system: the force inherent in the law does not take effect from outside the legal system but is a characteristic internal to the law. This is not simply a matter of interpretation. It must 
never be forgotten that "Legal decisions lead to people losing their homes or children, being sent back to their persecution and torture: legal interpretation leads to people losing their lives" (Douzinas \& Gearey 2005, p.72). As Shoshana Felman observes, "There is at least one crucial difference between an event of law and an event of art, no matter how dramatic they both are: a work of art cannot sentence to death" (Felman 2003, p.259).

Inextricably intertwined with the iterability of the law is an aporia: although justice demands that laws should be sufficiently general so as to enable like cases to be treated alike, it also requires the recognition of specific facts of each case. The problem of the aporia in which the law is caught is that laws are necessarily applied at times that are different from the point at which they are formulated and brought into being. Individual contexts in which laws have to be applied cannot all be anticipated when they initially come into being.

TM Clubcard provoked an acknowledgement of the aporia of the law by requiring decisions to be made by those who came before it; in the process it brought about a realisation of the violence of the law. Accordingly, the wider provocation of the work lay in the way it demystified the idea that "the law is a neutral and peaceful arbitrator, or means of achieving social order" (Sokoloff 2005, p.344). The decisions called for by TM Clubcard concerned the intellectual property of the supermarkets and their application of those rights. According to Baker most people understood the work was a parody. She describes how she "emailed all 45 members of the database asking if they had assumed I was the real Tescos. 3 replied that they had" (Baker 1997). The database was "dysfunctional" in the sense it was not associated with a supermarket, and as Baker pointed out the majority of those in the work's database realised that that was the case.

The supermarkets could be regarded as having unjustly asserted their intellectual property rights given the stability of the meaning of TM Clubcard as a parody. Iterability does not prevent "a relative stability of the dominant interpretation (including the 'self' interpretation) of the text being commented upon" (Derrida 1988, p.143). It means that "Such stabilization is relative, even if it is sometimes so great as to seem immutable and permanent" (Derrida 1988, p.145). The supermarkets sought to use the generality of the law to constrain the risk of iterability that Baker's work exemplified. As Derrida argues the "generality of the law is fundamentally heterogeneous to the specificity of the case" (Davies 2001, p.227). The law must necessarily fail to be just because no legal system is able to be general enough not to be violent; not to give rise to unjust outcomes because of the disjunction between its universal application and applications in any given set of circumstances.

The intellectual property rights asserted by the supermarkets, as with any replacement laws which might come into effect in the event of new legislation, could not be expressed in terms that are able to take into account every contingency, which in this case included the parody created by TM Clubcard. The supermarkets' use of intellectual property rights may be understood to have been used to try and assert the desired permanence of the connection between their respective identities and brands at the cost of allowing the existence of such a work of art.

\section{CONCLUSION}

My argument as to the unjust assertion by the supermarkets of their rights very much relies on the fact that the work's effectiveness depended on TM Clubcard eventually being understood as a parasite of the 'normal', legitimised, and commercial loyalty cards so that it could work as a contrast to such schemes. The critique would not have been effective unless the work was - at least initially taken to be a 'real' supermarket loyalty card site because of the appropriated branding. However, such a contrast (and with it a critique of the loyalty schemes) could not be created unless there was eventually awareness that the "dysfunctional" database was not associated with a supermarket loyalty card scheme.

It seems to me that for the three people who thought that TM Clubcard was operated by Tesco it could be said the work had failed to the extent it did not have the effect of allowing an awareness of the significance of the differences between the supermarket's loyalty card and the way in which TM Clubcard was operated by Baker. The need for the decision as to whether the work was 'genuine' or not made possible an awareness of the contingent nature of the ways by which corporations are enabled both to create and protect identity through the use of brands. The legal threats by the supermarkets had the effect of closing down the need for any decision as to whether the work was a parodying work of art or operating as a supermarket loyalty card. For the supermarkets the work was not acceptable; their branding must have calculable effects and "calculation is a dream of the erasure of contingency" (Mansfield 2006, p.480).

The nature of the work revealed the inability of those who came to it to be absolutely certain of its meaning and in doing so drew attention to the way in which iterability simultaneously both gives rise to and undermines the possibility of identity creation. The supermarkets, able to call upon the authority of 
the law, wanted branding to result in decisions being a matter of formality; it was desired that the presence of their respective logos would convey only their corporate identities. A database associated with a loyalty card scheme allows information to be obtained that can then be used to associate the brand with the various qualities claimed for the company identity. A 'real' loyalty card scheme contributes to the process of identity formation by reason of its database functionality. It has been pointed out, for example, that it was the use of a relational database that "made Wal-Mart [sic] the biggest retailer on earth, and Oracle the second largest software company behind Microsoft" by means of mining data for information (Stalbaum n.d.).

My argument is not that companies should never be able to hold people to account for the infringement of intellectual property rights as, apart from anything else, it is possible to characterise the use of branding by companies as being in the interests of others, including as consumers. But, in this instance, doing so unjustly foreclosed TM Clubcard from opening an awareness of the (in)competence that is inherent in the need to make decisions that frame the way in which the future unfolds in this time of ubiquitous real-time technologies. The law enabled the supermarkets to close down the work in response to their perceptions of the risk of decision-making and in the process revealed the implications of its violence in the formation of identity and the perpetuation of the way in which society is constructed.

\section{REFERENCES}

Ades, D., Cox, N. and Hopkins. D. (1999) Marcel Duchamp. Thames \& Hudson, London.

Baker, R. (1997) TM Clubcard: Remember Language is Not Free.

https://www.heise.de/tp/features/TM-Clubcard3563858.html (retrieved 19 March 2019).

Baker, R. (2019) TM Clubcard.

http://www.irational.org/tm/clubcard/ (retrieved 19 March 2019).

Davies, M. (2001) Legitimate Fictions. In Cohen, T. (ed.) Jacques Derrida and the Humanities: $A$ Critical Reader. Cambridge University Press, Cambridge.

Derrida, J. (1988) Limited Inc., Northwestern University Press, Evanston.
Derrida, J. (1990) Force of Law: The Mystical Foundation of Authority, Cardozo Law Review, 11, pp.919-1045.

Douzinas, C. and Gearey, A. (2005) Critical Jurisprudence: The Political Philosophy of Justice. Hart Publishing, Oxford \& Portland, Oregon.

Felman, S. (2003) A Ghost in the House of Justice: Death and the Language of the Law. In ed. by A. Sarat, A. \& Simon, J. (eds.). Cultural Analysis, Cultural Studies, and the Law. Duke University Press, London

Gibbons, J. (2005). Art \& Advertising. I.B.Tauris, London.

Harold, C. (2004) Pranking Rhetoric: 'Culture Jamming' as Media Activism. Critical Studies in Media Communication, 21(3) September, pp.189211.

Kornberger, M. (2010) Brand Society. Cambridge University Press, Cambridge.

Lury, C. (2004). Brands: the Logos of the Global Economy. Routledge, London \& New York.

Mansfield, N. (2006). Refusing Defeatism: Derrida, Decision and Absolute Risk, Social Semiotics, 16, pp.473-483

Paul, C. (2003). Digital Art. Thames \& Hudson, London.

Pilcher, J. (2016). State Britain and the Art of (Im)proper Democratic Protest, Law, Culture and the Humanities, 12 January 2016. https://doi.org/10.1177/1743872115625433 (retrieved 19 March 2019).

Raley, R. (2009). Tactical Media. University of Minnesota Press, Minneapolis \& London

Sokoloff, W. W. (2005). Between Justice and Legality: Derrida on Decision, Political Research Quarterly, 58:2, pp.341-352

Stalbaum, B. n.d. After Land Art: Database and the Locative Turn, http://www.intelligentagent.com/archive/Vol4 No4 f reerad afterlandart stalbaum.htm (retrieved 19 March 2019)

Stallabrass, J. (2003). Internet Art. Tate Publishing, London

Talbot, L. E. (2008). Critical Company Law. Routledge, Cavendish, Oxford. 